\title{
REFORMA TRABALHISTA, DESIGUALDADE E DESENVOLVIMENTO
}

\section{LABOR REFORM, INEQUALITY AND DEVELOPMENT}

\author{
Ana Elizabeth Neirão Reymão \\ Centro Universitário do Estado do Pará - CESUPA - (Belém, PA, Brasil) \\ Universidade Federal do Pará - UFPA - (Belém, PA, Brasil) \\ Shirley da Costa Pinheiro \\ Centro Universitário do Estado do Pará - CESUPA - (Belém, PA, Brasil) \\ Recebimento: 30 abr. 2018 \\ Aceitação: 30 ago. 2018
}

\begin{abstract}
Como citar este artigo / How to cite this article (informe a data atual de acesso / inform the current date of access):
REYMÃO, Ana Elizabeth Neirão; PINHEIRO, Shirley da Costa. Reforma trabalhista, desigualdade e desenvolvimento. Revista da Faculdade de Direito UFPR, Curitiba, PR, Brasil, v. 63, n. 3, p. 81-104, set./dez. 2018. ISSN 2236-7284. Disponível em: <https://revistas.ufpr.br/direito/article/view/59213>. Acesso em: 22 dez. $2018 . \quad$ DOI: http://dx.doi.org/10.5380/rfdufpr.v63i3.59213.
\end{abstract}

\section{RESUMO}

A Lei 13.467/2017 admite a negociação direta entre empregados e empregadores acerca de diversos aspectos relacionados às condições de trabalho. Preocupado com seus possíveis efeitos, este artigo objetiva discutir essa flexibilização de direitos, considerando a elevada desigualdade social brasileira e a questão da igualdade nessa negociação. Indaga-se, como problema de pesquisa, se a igualdade formal, pressuposta pela atual norma, é uma interpretação adequada à promoção do desenvolvimento e coerente com os objetivos fundamentais da República, expressos na Constituição Federal de 1988. Tem-se como referência as análises de Thomas Piketty (2014) e a teoria de Amartya Sen (2000), para quem o desenvolvimento é um processo de expansão das liberdades que as pessoas desfrutam, não restrito ao crescimento econômico. A pesquisa aqui apresentada é exploratória, de abordagem qualitativa, tendo como procedimentos o levantamento bibliográfico e documental, com consulta à nova legislação trabalhista e a textos oficiais dos discursos que acompanharam sua elaboração. $\mathrm{O}$ estudo conclui que a negociação de alguns direitos pode gerar ocupações que não contemplam a ideia de trabalho decente, uma vez que a igualdade material não está sendo garantida, podendo haver um aumento da desigualdade social no País.

PALAVRAS-CHAVE

Reforma Trabalhista. Desigualdade. Desenvolvimento. Flexibilização. Emprego.

\begin{abstract}
The Law 13,467/2017 admits the direct negotiation between workers and employers about many aspects related to working conditions. Concerned about its possible effects, this article aims to discuss this flexibilization of rights, considering the high social inequality in Brazil and the issue of equality in this negotiation. It is questioned, as a research problem, whether formal equality, presupposed by the current norm, is a proper interpretation to promote the development and consistent with the fundamental objectives of the Republic, expressed in the Constitution of 1988. The paper uses the analysis of Thomas Piketty (2014) and the theory of Amartya Sen (2000), for whom development is a process of expansion of the freedoms that people enjoy, not restricted to economic growth, as
\end{abstract}


references. The research is exploratory, with a qualitative approach, having as procedures the bibliographic and documentary survey, with consultation to the new labor legislation and official texts of the speeches that accompanied its elaboration. The study concludes that the negotiation of some rights can generate occupations that do not contemplate the idea of decent work, since material equality is not being guaranteed, and there may be an increase in social inequality in the country.

\section{KEYWORDS}

Labor Reform. Inequality. Development. Flexibilization. Employment.

\section{INTRODUÇÃO}

A nova legislação trabalhista, aprovada em 2017, permitiu, mediante acordo individual e sem a intermediação do sindicato ou do Estado, a negociação direta entre as partes da relação laboral acerca de diversos aspectos relacionados às condições de trabalho. Preocupado com os efeitos dessa inovação, o presente artigo tem por objetivo discutir essa flexibilização de direitos trabalhistas, considerando a elevada desigualdade social brasileira e a questão da igualdade nessa negociação.

Os direitos de igualdade e liberdade individual, bem como a presença do Estado para que a justiça social seja efetivamente alcançada e assim, de fato, oportunizar a redução da desigualdade social, são assegurados pela Constituição Federal (CF) de 1988 (CF/88). Erradicar a pobreza e reduzir as desigualdades sociais e regionais (art. $3^{\circ}$, III, CF) brasileiras é um dos objetivos fundamentais da República. A valorização do trabalho humano e a necessidade de assegurar a todos existência digna e promover a justiça social são expressamente mencionadas no artigo 170 da CF.

A CF/88 marcou a retomada democrática no País, afirmando a legitimidade dos direitos civis e políticos e a importância do Estado em garanti-los aos seus cidadãos. Em seu texto, os direitos sociais, como os trabalhistas, são tratados como direitos fundamentais. Porém, a crise econômica abriu espaço para reforçar as já muitas críticas à legislação trabalhista. Sob o argumento de ser antiga, a Consolidação das Leis do Trabalho (CLT), datada de 1943, foi acusada de garantir proteção excessiva aos trabalhadores, estando dissociada do século XXI e do incentivo à iniciativa privada.

Com base nesse discurso, foi aprovada a nova legislação do trabalho, sob n. ${ }^{\circ}$ 13.467, de 13 de junho de 2017, complementada pela já extinta Medida Provisória n. ${ }^{\circ}$ 808, de 14 de novembro de 2017. Intitulada de Reforma Trabalhista, ela trouxe uma maior flexibilização dos direitos trabalhistas, com a prevalência do negociado sobre o legislado e com a interferência mínima do Estado, seja de forma preventiva, por meio dessa nova legislação, ou de forma repressiva, pelo Poder Judiciário.

Uns dos principais objetivos da Reforma informados pelo governo, tanto no discurso do Presidente da República, Michel Temer, quanto por seu relator, Deputado Rogério Marinho, foi gerar 
o crescimento econômico e combater o desemprego, viabilizando maior formalidade no mercado de trabalho e rendas à população, graças ao aumento dos investimentos que dela decorreriam.

Para tal, alguns artigos da Lei n. ${ }^{\circ} 13.467$ viabilizam a negociação direta entre empregado e empregador, sem a intermediação do Estado ou do sindicato, de horas extras (art. 59), do banco de horas (art. 59, § 5 $5^{\circ}$ CLT), da compensação de jornada (art. 59, § $6^{\circ}$ CLT), de uma jornada $12 \times 36$ (art. 59-A CLT), do parcelamento de férias (art. 134, §1 $1^{\circ}$ CLT), do intervalo para lactante (art. 396, §2 CLT), da demissão em comum acordo (art. 484-A CLT), e do contrato de trabalho - para funcionários com nível superior e que recebem salário igual ou superior a duas vezes o limite máximo dos benefícios do Regime Geral de Previdência Social (art. 444, § único, CLT).

Ocorre que não se pode ignorar que o Brasil é um dos países mais desiguais do mundo. Em 2016, o ganho médio de uma pessoa pertencente ao grupo do $1 \%$ mais rico da população era equivalente a 36 vezes o ganho daquelas no grupo da metade mais pobre do País, segundo dados da Pesquisa Nacional por Amostra de Domicílios (Pnad) Contínua, do Instituto Brasileiro de Geografia e Estatística (IBGE). Esse privilegiado grupo era composto por apenas 889 mil pessoas, para as quais o rendimento médio foi de R \$ 27 mil ao mês, no referido ano. No grupo dos 50\% com menor renda, formado pelo expressivo contingente de 44,4 milhões pessoas, a renda média era de R \$ 747 por mês, inferior ao salário mínimo vigente à época.

Nesse contexto, certamente é importante que o país cresça economicamente, mas é preciso lembrar que isso não reduz, automaticamente, a desigualdade social. Estudos como os de Thomas Piketty (2014) recolocaram esse problema em foco e revelam quão equivocado é acreditar que o crescimento da renda nacional é seguido de uma inexorável redução da desigualdade e aumento de bem-estar, de desenvolvimento. Pesquisas realizadas pela World Wealth and Income Database, sob a coordenação do autor, concluíram que, entre 2001 e 2016, a desigualdade da renda no Brasil não foi reduzida, evidenciando que o crescimento econômico do período teve pouco impacto nessa variável.

Considerando essa realidade, a igualdade formal pressuposta na negociação direta entre empregado e empregador sobre as condições de trabalho, proposta pela Reforma Trabalhista, é uma interpretação adequada à promoção do desenvolvimento e coerente com os objetivos fundamentais da República Federativa do Brasil, expressos na CF/88?

Tendo como base esse problema de pesquisa, a hipótese de trabalho é de que a nova legislação considerou apenas a igualdade formal, ignorando a ausência de igualdade material entre os envolvidos nessa negociação e o estabelecido no texto constitucional acerca da justiça social.

O estudo tem como referencial teórico os ensinamentos de Amartya Sen (2000), para quem o desenvolvimento é um processo de expansão das liberdades que as pessoas desfrutam, não restrito 
ao crescimento econômico, como será mostrado. Com base em Piketty (2014), defende-se a importância de políticas públicas para a redução da desigualdade e, por conseguinte, aproximar as economias da noção de desenvolvimento que pressupõe a melhoria generalizada da condição humana.

Argumenta-se, ainda, que esse desenvolvimento requer que as instituições, definidas como as “regras do jogo” por North (1990), viabilizem um círculo virtuoso de inclusão e redução de desigualdades. Assim, partindo das análises de Acemoglu e Robison (2012), a legislação trabalhista, enquanto instituição, deve ser inclusiva, afastando a sociedade brasileira de sua trajetória de desenvolvimento desigual.

Em termos metodológicos, a pesquisa aqui apresentada é, quanto aos objetivos, exploratória. A abordagem é qualitativa e, como procedimentos, usou-se o levantamento bibliográfico e documental, com consulta à nova legislação trabalhista e a textos oficiais dos discursos que acompanharam sua elaboração.

Após essa introdução, o texto trata da importância dos direitos fundamentais trabalhistas e da flexibilização decorrente da Reforma em análise, na qual se insere a negociação direta entre empregado e empregador sobre as condições de trabalho. A seção dois discute a relação entre desigualdade, crescimento econômico e desenvolvimento, destacando que o crescimento nem sempre se traduz em melhoria da vida e das liberdades que as pessoas desfrutam. A CF/88 e a desigualdade brasileira são temas da seção três. Em seguida, o artigo destaca a importância das instituições para o desenvolvimento e questiona o contexto em que ocorrerá a negociação direta entre as partes da relação laboral acerca de aspectos das condições de trabalho, como estabelecido na nova legislação. As conclusões do estudo são apresentadas na última parte do texto.

\section{DIREITOS FUNDAMENTAIS TRABALHISTAS E A FLEXIBILIZAÇÃO DECORRENTE DA REFORMA}

Direitos fundamentais "são os que, em dado momento histórico, fundados no reconhecimento da dignidade da pessoa humana, asseguram a cada homem as garantias de liberdade, igualdade, solidariedade, cidadania e justiça” (ROMITA, 2007, p. 45). A dignidade é o verdadeiro pressuposto ou o próprio fundamento dos direitos humanos ou fundamentais sendo o homem o fim em si mesmo, como Kant (1974, p. 229) escreveu:

O homem é, duma maneira geral, todo o ser racional, existe com o fim em si mesmo, não só como meio para o uso arbitrário desta ou daquela vontade. Pelo contrário, em todas as suas ações, tanto nas que se dirigem a ele mesmo como nas que se dirigem a outros seres racionais, ele tem sempre de ser considerado simultaneamente como fim [...] [O]s seres racionais se 
chamam pessoas porque a natureza os distingue como fins em si mesmos, quer dizer, como algo que não pode ser empregado como simples meio.

Na Constituição Federal de 1988 (CF/88), os direitos sociais são tratados como direitos fundamentais. Em seu art. $6^{\circ}$, estabelece:

Art. 6 - São direitos sociais a educação, a saúde, a alimentação, o trabalho, a moradia, o transporte, o lazer, a segurança, a previdência social, a proteção à maternidade e à infância, a assistência aos desamparados, na forma desta Constituição.

Dentre eles, destacam-se os direitos trabalhistas que, com suas garantias, são essenciais nas relações de produção, por sua importância para a economia e por ser fator de inclusão social.

O trabalho, ao ser dotado de valor social e econômico, levou o constituinte a tratá-lo como fundamento do Estado democrático de direito, bem como a dignidade da pessoa humana:

Art. $1^{\circ}$ - A República Federativa do Brasil, formada pela união indissolúvel dos Estados e Municípios e do Distrito Federal, constitui-se em Estado Democrático de Direito e tem como fundamentos:

[...]

III - a dignidade da pessoa humana;

[...]

IV - os valores sociais do trabalho e da livre iniciativa.

A CF/88 não se limitou, entretanto, a prever direitos, mas instituiu diversas garantias e determinações para efetivá-los, entre as quais a proibição de retrocesso social e o compromisso de implementação progressiva dos direitos sociais que representam categoria de direitos de segunda dimensão ${ }^{1}$.

A valorização do trabalho implica respeitar, pelo menos, o patamar mínimo representado pelo conceito de trabalho decente a que alude a Organização Internacional do Trabalho (OIT), relacionados à igualdade no trabalho; ao trabalho em condições justas, inclusive relativa à remuneração, e que preservem a saúde e segurança; à proibição do trabalho infantil; à liberdade sindical; além da proteção contra os riscos sociais, como ensina Romita (2007).

A elevação dos direitos dos trabalhadores à categoria de direitos fundamentais representa limitação ao exercício dos poderes do empregador à negociação flexibilizadora das condições de trabalho. Portanto, os direitos da personalidade (honra, intimidade, imagem); liberdade ideológica; liberdade de expressão e de informação; igualdade de oportunidades e tratamento; não discriminação; idade mínima de admissão ao emprego; salário-mínimo; saúde e segurança do trabalho; proteção

\footnotetext{
1 Usa-se aqui a expressão “dimensão”. Alguns preferem "geração”, mas esse é considerado um termo inadequado por parte da doutrina estrangeira e nacional, podendo passar a ideia de substituição de uma geração por outra, quando na verdade os novos direitos fundamentais reconhecidos se acumulam e se completam. Assim, o termo mais utilizado para a moderna doutrina é “dimensão”. Esse é o entendimento de E. Riebel e de Paulo Bonavides, citados por Sarlet (2015).
} 
contra a despedida arbitrária; direito ao repouso (intervalos, limitação da jornada, repouso semanal remunerado e férias); direito de sindicalização; direito de representação dos trabalhadores e sindical na empresa; direito à negociação coletiva; direito de greve; direito ao ambiente de trabalho saudável, devem ser respeitados em uma negociação (ROMITA, 2007, p. 422).

Na aprovação da nova legislação trabalhista, quer dizer, da Lei 13.467/2017², o discurso político foi a necessidade de modernização das normas trabalhistas, com um olhar voltado para o século XXI, visando uma melhoria no mercado de trabalho, com mais renda e emprego.

Nesse contexto, observou-se uma ampla alteração nas relações de trabalho no Brasil, com mudanças em mais de 117 artigos da Consolidação das Leis do Trabalho (CLT) e nas Leis 8.213/91 e 8.036/90, impactando em mais de duzentos dispositivos legais do direito material e do direito processual trabalhista.

Entre algumas dessas alterações, tem-se que a jornada de trabalho poderá ser de doze horas seguidas por trinta e seis horas ininterruptas de descanso (art. 59-A da Lei 13.467/2017); deixaram de ser consideradas dentro da jornada de trabalho as atividades, no âmbito da empresa, como descanso, estudo, alimentação, interação entre colegas, higiene pessoal e troca de uniforme (art. $4^{\circ}, \S 2^{\circ}$ ); o pagamento do piso ou salário mínimo deixou de ser obrigatório na remuneração por produção e trabalhadores e empresas poderão negociar todas as formas de remuneração, as quais não precisam fazer parte do salário (art. 611-A); foi criado o contrato intermitente ${ }^{3}$ (art. 443); e a contribuição sindical passou a ser opcional (art. 578). Tem-se ainda a autorização para que para trabalhadores terceirizados, ainda que exercentes de mesma função que os empregados das empresas contratantes ${ }^{4}$, percebam salário inferior e, ainda, as condenações à sucumbência e ao pagamento de honorários por litigância de má-fé.

No novo texto, chama a atenção a nova redação do art. 611-A da CLT, conforme Lei $\mathrm{n}^{\circ}$ 13.467/2013. Dispõe ele que a convenção coletiva e o acordo coletivo de trabalho, observados os

\footnotetext{
2 Esse foi o mesmo discurso da edição da Medida Provisória n. ${ }^{\circ}$ 808/2017, de 14 de novembro de 2017. A mesma trouxe mudanças ao texto da referida lei e poderia ter sido um instrumento para auxiliar na melhor compreensão e assimilação pela sociedade das mudanças trazidas, mas não cumpriu sua função, por não ter sido votada pelo Congresso Nacional no prazo constitucional. Esse era o quadro até a data de finalização deste artigo, em 29 de abril de 2018.

3 A Lei n. 13.467/17 acresceu à CLT os artigos 452-A e seguintes e alterou o seu art. 443 para criar o contrato intermitente. É um contrato que deve ser celebrado por escrito, nos casos em que os serviços são transitórios, descontínuos, permitindo a alternância entre períodos de trabalho e de inatividade. Uma das preocupações relacionadas a ele é que esse trabalhador é excluído de alguns direitos estendidos aos demais empregados, pois não lhe é assegurada uma quantidade mínima de trabalho e renda por mês ou por ano.

4 A Reforma Trabalhista trouxe novidades para as empresas que fornecem mão de obra e, contrariamente ao que era decidido na Justiça do Trabalho, deixou de fazer a distinção entre atividades-fim e atividades-meio, permitindo que toda e qualquer atividade possa ser terceirizada.
} 
incisos III e VI do art. $8^{\circ}$ da CF/88, têm prevalência sobre a lei quando, entre outros, dispuserem sobre quinze itens listados ${ }^{5}$, que incluem temas desde a jornada de trabalho até a participação nos resultados da empresa.

Destaca-se, especialmente, o fato de que alguns artigos possibilitam a negociação direta entre empregado e empregador, sem a intermediação do sindicato ou do Estado, quais sejam: horas extras (art. 59), banco de horas (art. 59, § 5 CLT), compensação de jornada dentro do mês (art. 59, § $6^{\circ} \mathrm{CLT}$ ), jornada $12 \times 36$ (art. 59-A CLT), parcelamento de férias em até três períodos (art. 134, $\S 1^{\circ}$ CLT), intervalo para lactante (art. 396, §2 ${ }^{\circ}$ CLT), demissão em comum acordo (art. 484-A CLT), e contrato de trabalho - para funcionários com nível superior e que recebem salário igual ou superior a duas vezes o limite máximo dos benefícios do Regime Geral de Previdência (art. 444, § único, CLT).

O objetivo central dessas modificações seria o crescimento econômico do País, uma vez que os custos da manutenção de um emprego formal no Brasil, sob a égide da legislação trabalhista de 1943, seriam muito altos, inviabilizando os empresários de contratar novos empregados, mantê-los no emprego ou mesmo operar seu desligamento, assim como fazer investimentos. Enfim, diminuir os riscos e custos das empresas, aumentando suas margens de lucros para possíveis investimentos.

Abaixo, trechos do discurso do Presidente da República Michel Temer ${ }^{6}$, durante cerimônia de sanção do que chamou a "Lei de Modernização Trabalhista”, no Palácio do Planalto:

[...] E, portanto, na cerimônia de hoje, que eu assino a sanção da lei de modernização trabalhista, não precisamos registrar que foi árduo o percurso que nos trouxe até este momento.

[...] nós estamos, na verdade, é voltando o nosso trabalho para a área social. E, no geral, o nosso trabalho é para combater o desemprego. E combater o desemprego significa preocuparse com o social. E, para tanto, é preciso, naturalmente, prestigiar a iniciativa privada.

Pautado nessa argumentação, vários pontos da CLT de 1943 foram alterados, como mencionado, de modo a prevalecer a autonomia da negociação das partes da relação laboral (empregado e empregador) sobre o legislado, possibilitando a flexibilização de direitos.

\footnotetext{
5 Os itens são: “I - pacto quanto à jornada de trabalho, observados os limites constitucionais; II - banco de horas anual; III - intervalo intrajornada, respeitado o limite mínimo de trinta minutos para jornadas superiores a seis horas; IV - adesão ao Programa Seguro-Emprego (PSE), de que trata a Lei no 13.189, de 19 de novembro de 2015; V - plano de cargos, salários e funções compatíveis com a condição pessoal do empregado, bem como identificação dos cargos que se enquadram como funções de confiança; VI - regulamento empresarial; VII - representante dos trabalhadores no local de trabalho; VIII - teletrabalho, regime de sobreaviso, e trabalho intermitente; IX - remuneração por produtividade, incluídas as gorjetas percebidas pelo empregado, e remuneração por desempenho individual; $\mathrm{X}$ - modalidade de registro de jornada de trabalho; XI - troca do dia de feriado; XII - enquadramento do grau de Insalubridade; XIII - prorrogação de jornada em ambientes insalubres, sem licença prévia das autoridades competentes do Ministério do Trabalho; XIV - prêmios de incentivo em bens ou serviços, eventualmente concedidos em programas de incentivo; XV - participação nos lucros ou resultados da empresa.”

${ }^{6}$ Discurso realizado em 12.12.2017.
} 
A exposição de motivos da CLT de $1943^{7}$, por outro lado, deixava bem claro que seu objetivo era a intervenção do Estado como forma de garantir o equilíbrio da relação capital-trabalho e, assim, garantir os direitos fundamentais do trabalhador:

28. Em relação aos contratos de trabalho, cumpre esclarecer que a precedência das “normas” de tutela sobre os "contratos” acentuou que a ordem institucional ou estatutária prevalece sobre a concepção contratualista.

29. A análise do conteúdo da nossa legislação social provava exuberantemente a primazia do caráter institucional sobre o efeito do contrato, restrito este à objetivização do ajuste, à determinação do salário e à estipulação da natureza dos serviços e isso mesmo dentro de “standards” e sob condições preestabelecidas na lei.

Ao contrário, a nova legislação, que alterou a CLT de 1943, nasceu sob o prisma do liberalismo que, como explica Dworkin (2002), impulsiona a política e os políticos. Neste aspecto, passou a prevalecer a negociação das partes, com a limitação da intervenção do Estado, este também, representado pelo Poder Judiciário, passando a analisar questões meramente formais e não do mérito do acordado pelas partes, como se observa a seguir:

\section{Art. $8^{\circ}[\ldots]$}

$\S 2^{\circ}$. Súmulas e outros enunciados de jurisprudência editados pelo Tribunal Superior do Trabalho e pelos Tribunais Regionais do Trabalho não poderão restringir direitos legalmente previstos nem criar obrigações que não estejam previstas em lei.

$\S 3^{\circ}$. No exame de convenção coletiva ou acordo coletivo de trabalho, a Justiça do Trabalho analisará exclusivamente a conformidade dos elementos essenciais do negócio jurídico, respeitado o disposto no art. 104 da Lei no 10.406, de 10 de janeiro de 2002 - Código Civil, e balizará sua atuação pelo princípio da intervenção mínima na autonomia de vontade coletiva.

[...]

Art. 444 [...], parágrafo único. A livre estipulação a que se refere o caput deste artigo aplicase às hipóteses previstas no art. 611-A desta Consolidação, com a mesma eficácia legal e preponderância sobre os instrumentos coletivos, no caso do empregado portador de diploma de nível superior e que perceba salário mensal igual ou superior a duas vezes o limite máximo dos benefícios do Regime Geral de Previdência.

A modificada CLT possibilitou, dessa forma, flexibilizar direitos trabalhistas relativos à duração da jornada diária e semanal; férias; tempo de percurso; trabalho remoto; intervalo intrajornada; registro de jornada e salário, por meio da negociação direta entre empregado e empregador (DELGADO; DELGADO, 2017).

Todos esses direitos estão relacionados às condições de trabalho e são impactantes na própria vida, como ser humano, do trabalhador, uma vez que não há como dissociar a força de trabalho e modo de vida do trabalhador, daí que interligados à própria dignidade do trabalhador e, por isso, escalonados à categoria de direitos humanos e, portanto, direitos fundamentais (SARLET, 2015, p. 57).

\footnotetext{
7 Decreto-Lei 5.452, de 1.5.1943.
} 
A flexibilização de direitos, em si, acordada por partes em igualdade de condições, é passível de ser justa. Porém, à medida que o salário ainda figura com caráter alimentar e impõe a sujeição do trabalhador ao emprego, por necessidade de subsistência, a situação muda e torna-se preocupante (ROMITA, 2007, p. 419). Eis a razão da defesa, por muitos, da presença do Estado Social, atuando de forma preventiva, por meio de uma legislação protetiva ou, repressivamente, por um Judiciário forte, independente e autônomo.

O risco da flexibilização de direitos trabalhistas fundamentais sem a igualdade de condições das partes (empregado e empregador) pode gerar a sonegação dos direitos e afetar a dignidade do trabalhador e a esperada geração de renda pelo emprego formal, com a melhoria das condições de trabalho, do crescimento do mercado consumidor e a estabilização social se tornando um sonho a não ser alcançado.

As modificações legislativas relativas à prevalência do negociado sobre o legislado, se não forem aliadas a políticas públicas voltadas para compensar a distorção de igualdade entre empregado e empregador, poderão implicar a precarização das condições de trabalho, gerando o crescimento de trabalho não decente, nos termos apresentados pela OIT.

Considerando os ideais correlatos de igualdade e de liberdade, os indivíduos têm liberdade para firmarem seus relacionamentos jurídicos com outras pessoas e são detentores de direitos iguais perante a lei, independente do status ou posição social. Porém, apesar da ampla liberdade formal que a CF/88 confere, as circunstâncias materiais, em particular a distribuição de riqueza e as condições de trabalho, privam essas liberdades formais em sentido e valor. Isso tende a se agravar em um contexto de baixo crescimento econômico, como se discute na seção a seguir.

\section{CRESCIMENTO ECONÔMICO, REDUÇÃO DA DESIGUALDADE E DESENVOLVIMENTO}

Em um país em crise econômica ${ }^{8}$ e com flagrante desigualdade social, o salário ainda figura como de natureza estritamente alimentar para a maioria dos trabalhadores brasileiros e, quando assim se estabelece, a igualdade das partes na relação capital-trabalho deixa de existir em uma negociação.

No trimestre encerrado em março de 2018, o índice de desemprego no Brasil atingiu 13,1\%, o maior nível desde maio do ano anterior, segundo dados da Pnad, do IBGE. Isso significa que 13,7

\footnotetext{
8 Dados do Instituto Brasileiro de Geografia e Estatística (IBGE) mostram que, embora tenha ocorrido um pequeno crescimento no terceiro trimestre de 2017 (0,1\%), o Produto Interno Bruto (PIB) do Brasil ainda está em níveis muito baixos, principalmente em relação aos demais países: "Um ranking da expansão no terceiro trimestre, na comparação anual, elaborado pela Austin Rating mostra o Brasil em antepenúltimo em uma lista de 47 países” (CURY; SILVEIRA, 2017, p. 1).
} 
milhões de pessoas estavam desempregadas no País. A população ocupada, por sua vez, ficou em 90,6 milhões, representando uma queda de 1,7\% em relação ao trimestre encerrado em dezembro, quando era de 92,1 milhões.

A pesquisa mostra que o número de empregados com carteira de trabalho assinada (32,9 milhões) caiu 1,2\% ante o trimestre encerrado em dezembro de 2017, significando uma redução de 408 mil pessoas. Já o número de trabalhadores por conta própria (23 milhões de pessoas), embora estável na comparação com aquele trimestre, teve ligeira alta de 3,8\% (mais 839 mil pessoas) em relação ao mesmo período do ano anterior.

Onde está o alegado “impulso para o Brasil não parar”, que viria com a "Lei de Modernização Trabalhista”? A lei mudou e, com ela, as relações de trabalho. Mas ao contrário do anunciado no já citado discurso proferido no Palácio do Planalto, ou dos milhões de postos de trabalho que projetava o Relator da Reforma Trabalhista, Deputado Federal Rogério Marinho, o que se tem visto é o contrário.

Por outro lado, verificou-se uma forte queda no estoque de processos, ou seja, no volume de litígios à espera de solução na Justiça do Trabalho: 6,4\% em fevereiro de 2018 (FERNANDES; CASTANHO, 2018, p. 1). Infelizmente isso não foi resultado de maior produtividade dos magistrados, de uma aceleração dos julgamentos ou de um aumento do número de casos julgados: "Entre dezembro de 2017 e fevereiro deste ano, os juízes trabalhistas proferiram quase 2\% menos sentenças. Os casos julgados caíram de 490,2 mil para 481,4 mil” (FERNANDES; CASTANHO, 2018, p. 1).

Há fortes evidências de que o impacto estrutural causado com as mudanças na legislação do trabalho tem deixado os trabalhadores temerosos, notadamente pela insegurança quanto às novas regras $^{9}$. Além dos mais de 20 questionamentos no Supremo Tribunal Federal (STF) sobre a inconstitucionalidade do texto, um dos pontos que mais tem preocupado os trabalhadores é a série de decisões na Justiça exigindo pagamento de custas processuais. As condenações à sucumbência e ao pagamento de honorários por litigância de má-fé certamente alteraram seu comportamento, mas em que medida isso é um indicativo de uma justiça funcionando melhor?

Não há como negar que essa insegurança jurídica tende a piorar a desigualdade social no Brasil. Dentre os que festejaram a Reforma em análise, há os que afirmam que, em alguns casos, os trabalhadores vinham sendo beneficiados com acordos ou ganhos que as empresas preferiam firmar para não serem condenadas a valores maiores. Sob o argumento de que a Justiça do Trabalho é paternalista, negam o conflito distributivo que está por trás das demandas trabalhistas, o que é bastante

${ }^{9} \mathrm{O}$ artigo $6^{\circ}$ da Lei 13.467 estabeleceu que ela entraria em vigor 120 dias após a sua publicação oficial, o que ocorreu no dia 11 de novembro de 2017. 
injusto, na medida em que a imensa maioria dos empregados é hipossuficiente, se comparada à maioria dos patrões.

Deixam de considerar que muitos trabalhadores têm grande dificuldade de provar seus direitos, pois a documentação deles, por exemplo, está sempre nas mãos do empregador ou simplesmente não existe, o que torna os direitos muito frágeis.

Creem na tese de que a Reforma Trabalhista promoverá o crescimento econômico e esse, por si só, será capaz de reduzir as desigualdades. Ora, ainda que a desigualdade não seja necessariamente algo negativo, é relevante estar atento às suas causas. Como assevera Piketty (2014, p. 26): “a desigualdade não é necessariamente um mal em si: a questão central é decidir se ela se justifica e se há razões concretas para que ela exista”.

Ensina o autor que o crescimento econômico não produz, por si só, o fim da desigualdade social. Seus estudos apontam a fragilidade em se pensar em crescimento econômico do país seguido da redução da desigualdade e aumento de bem-estar, ou seja, do desenvolvimento social e econômico.

Nos estudos e debates acadêmicos do pós-Guerra, tanto as universidades como as organizações internacionais adotavam as expressões crescimento e desenvolvimento econômico como sinônimos. Mostra Piketty (2014) que essa visão foi muito influenciada pelas ideias de Simon Kuznets ${ }^{10}$, um importante economista americano e professor de Harvard, que formulou, em 1953, a tese conhecida como curva de Kuznets, segundo a qual a industrialização levaria a um crescimento da desigualdade somente até determinado patamar. Depois desse ponto máximo, sua tendência seria a redução natural. Argumentava o autor que, à medida que a industrialização se generalizasse, a desigualdade seria continuamente reduzida. Assim, as sociedades modernas, organizadas como democracias, fariam a igualdade formal traduzir-se em igualdade econômica. Quer dizer, a “modernização industrial” e a democracia resultariam em menor desigualdade no longo prazo.

Essa ideia de que a desigualdade primeiramente cresce para depois cair, foi formulada por motivos errados e baseada em dados empíricos frágeis, defende Piketty (2014). O próprio Kuznets era consciente do caráter especulativo de sua teoria, tanto que se preocupou em esclarecer que a intenção de suas previsões otimistas era simplesmente manter os países subdesenvolvidos “na órbita do mundo livre”. “Em grande medida, portanto, a teoria da “curva de Kuznets” é produto da Guerra Fria” (PIKETTY, 2014, p. 21).

Ainda assim, por muito tempo essa noção foi tomada como inexorável, como entre os que defenderam as vantagens da Reforma Trabalhista. Piketty (2014) mostra que não. Mesmo que o

\footnotetext{
10 Simon Kuznets foi um economista russo naturalizado estadunidense. Segundo ele, a desigualdade poderia ser descrita,
} em toda parte, por uma curva em forma de sino, conhecida como curva de Kuznets (PIKETTY 2014, p. 21). 
aumento da desigualdade viesse acompanhado de crescimento econômico, a ideia assenta-se numa visão harmônica desse processo e descarta a necessidade de qualquer intervenção do Estado para reduzi-la, pois além de associar industrialização a desenvolvimento, influenciou muitos autores a compreenderem a redução da desigualdade a partir de determinado ponto como uma simples decorrência da primeira.

O desenvolvimento no entretanto, é um fenômeno complexo e tem uma miríade de causas, o que leva a maioria dos cientistas sociais a repudiar teorias simples, de aplicação ampla e que identificam uma única causa para os acontecimentos, ensinam Acemoglu e Robison (2012).

Não resta dúvida de que os aspectos econômicos são importantes, mas certamente são insuficientes para dar conta da complexa noção de bem-estar que está por trás do conceito de desenvolvimento. Dentre as várias teorias que se dedicam à compreensão desse fenômeno relativo à melhoria do padrão de vida das pessoas, cabe aqui lembrar dos ensinamentos de Amartya Sen.

Para ele, o desenvolvimento é um processo de expansão das liberdades que as pessoas desfrutam, não restrito ao crescimento econômico e ao aumento de rendas, decorrentes da industrialização ou avanço tecnológico (SEN, 2000, p. 17). Certamente a expansão das liberdades depende de outras influências, daquilo que o autor denomina "remoção das fontes de privação das liberdades: pobreza e tirania, carência de oportunidades econômicas e destituição social sistemática, negligência dos serviços públicos e intolerância ou interferência excessiva de Estados repressivos” (SEN, 2000, p. 18).

Para o exercício da liberdade, são necessários funcionamentos e capacidades, defende o autor. Os funcionamentos (functionings) estão ligados àquilo que uma pessoa poderá considerar como importante ter, ser ou desfrutar: educação, saúde, habitação, nutrição adequada, além de sua participação na vida da comunidade e respeito próprio, por exemplo. Assim, trata-se de um conceito relacionado às atividades ou estados de existência importantes para a pessoa levar o tipo de vida que ela valoriza.

As capacidades (capabilities), por sua vez, relacionam-se às combinações alternativas de funcionamentos que podem ser realizados pela pessoa. Trata-se da capacidade de uma pessoa realizar suas próprias escolhas, a partir do conjunto de funcionalidades de que dispõe.

Relacionam-se às combinações alternativas de funcionamentos possíveis de realização por uma pessoa:

A capacidade (capability) de uma pessoa consiste nas combinações alternativas de funcionamentos cuja realização é factível para ela. Portanto, a capacidade é um tipo de liberdade: a liberdade substantiva de realizar combinações alternativas de funcionamentos 
(ou, menos formalmente expresso, a liberdade para ter estilos de vida diversos) (SEN, 2000, p. 95).

Como explica o autor, alguém pode passar fome porque está em jejum. Outra pessoa, porque está desnutrida. Ocorre que o conjunto capacitário da pessoa $A$ é diferente do da pessoa $B$, pois a primeira pode escolher comer bem e ser nutrida, o que não ocorre com a segunda.

O conjunto capacitário de uma pessoa depende das alternativas que ela possui, das suas oportunidades reais. Daquilo que ela é substancialmente livre para fazer (SEN, 2000, p. 96).

Nesse contexto, o desenvolvimento está relacionado à capacidade que os indivíduos têm de liberdade, o elemento constitutivo básico do desenvolvimento, na visão de Sen (2000). Liberdade como capacidade de as pessoas levarem o tipo de vida que elas valorizam, um conceito multiforme e que envolve considerações sobre processos e oportunidades substantivas.

Mas estariam os trabalhadores acionando menos a Justiça do Trabalho porque são livres para assim agir ou teriam suas oportunidades reais sido reduzidas com a Reforma Trabalhista?

Ora, as capacidades individuais dependem, de forma decisiva, das disposições econômicas, sociais e políticas. O Estado e a sociedade têm papéis fundamentais no fortalecimento e na proteção das capacidades humanas. Assim, embora a liberdade de participar do intercâmbio econômico, dos mercados, tenha um papel básico na vida social, isso não isenta o Estado de sua atuação social, administrativa e regulatória, que pode acelerar ou retardar a superação da pobreza e as desigualdades.

Para Sen (2010), o sistema capitalista não é impeditivo para se alcançar o desenvolvimento, mas é preciso que haja ética de comportamento e que suas instituições estejam bem alicerçadas, de modo que as partes cumpram o contratual, sem excesso de cobiça.

Nesse aspecto, a negociação entre empregado e empregador, com menor intervenção do Estado poderia contribuir para o desenvolvimento econômico, desde que os funcionamentos básicos das pessoas fossem assegurados. Assim, políticas públicas de educação, por exemplo, melhoram as chances de os trabalhadores terem ciência dos seus direitos e dá equilíbrio à negociação entre capital e trabalho. Contudo, a sua negação, associada a baixos rendimentos, oriundos de trabalho não decente, atuam em sentido contrário a este equilíbrio e, portanto, ao desenvolvimento como liberdade.

Pessoas não podem ser vistas apenas como um recurso produtivo, de forma a ser menosprezada a natureza humana dos trabalhadores. O conceito de capital humano possui sua utilidade, mas deve ser visto de forma a adicionar e incluir a capacidade humana e sua influência direta para o bem-estar e liberdade das pessoas (SEN, 2000).

Nesse sentido, a nova legislação deve ser capaz de gerar trabalho decente e não simplesmente ocupações com condições e salários não dignos, consideradas subempregos. Para tanto, faz-se 
necessário que os direitos fundamentais sejam limites à flexibilização irrestrita entre empregado e empregador e que, paralelamente, sejam implementadas políticas públicas em favor da ampliação dos funcionamentos, como a difusão do conhecimento e da educação de qualidade, para que, assim, as partes envolvidas na negociação laboral tenham, efetivamente, liberdade de escolhas e, dessa forma, se possa alcançar o desenvolvimento.

Considerando o nível de desigualdade brasileira, há condições para os trabalhadores brasileiros negociarem com os seus empregadores sem terem seus direitos precarizados? Com direitos sonegados, não surgirão empregos decentes. Com subempregos, poderá até haver o crescimento econômico, mas jamais o desenvolvimento.

Nessa perspectiva, não se pode ignorar que a redução da desigualdade social é um dos objetivos da República Federativa do Brasil, como se discute a seguir.

\section{A CONSTITUIÇÃO FEDERAL DE 1988 E A PREOCUPAÇÃo COM A DESIGUALDADE BRASILEIRA}

O direito à igualdade tem sido abordado em várias Constituições brasileiras. Na atual Carta Magna não foi diferente, estando tal postulado expresso em diversos dispositivos.

A Constituição Federal de 1888 (CF/88) define no artigo 5:

Todos são iguais perante a lei, sem distinção de qualquer natureza, garantindo-se aos brasileiros e aos estrangeiros residentes no País a inviolabilidade do direito à vida, à liberdade, à igualdade, à segurança e à propriedade, nos termos seguintes:

Em seu artigo $3^{\circ}$, estabelece:

Constituem objetivos fundamentais da República Federativa do Brasil:

$[\ldots]$

III - erradicar a pobreza e a marginalização e reduzir as desigualdades sociais e regionais.

Mais adiante, no artigo 170 ressalta:

A ordem econômica, fundada na valorização do trabalho humano e na livre iniciativa, tem por fim assegurar a todos existência digna, conforme os ditames da justiça social, observados os seguintes princípios:

$[\ldots]$

VII - redução das desigualdades regionais e sociais.

Todavia, a mera previsão legal não tem se mostrado suficiente. Mesmo a igualdade estando expressa nos textos normativos, não impede que a realidade permita toda a sorte de desigualdades, como a de renda e riqueza. 
Dados do Radar IDHM (IPEA, 2017, p. 9) mostram que, apesar das melhoras nos indicadores de desenvolvimento humano observadas no Brasil entre 2000 e 2010, no período mais recente, 2011 a 2015, quase todos apresentaram taxa de crescimento anual inferior à observada para o período intercensitário. Quer dizer, apesar da redução da pobreza no País na última década, ela não foi suficiente para traçar uma tendência de longo prazo para a queda das desigualdades sociais no País. Alerta o estudo sobre o aumento da pobreza e a queda da renda, bem como da importância de políticas públicas voltadas ao crescimento do emprego, da renda e do combate à desigualdade:

\begin{abstract}
Especial atenção deve ser dada aos indicadores relativos à pobreza, emprego e renda, considerando o momento de desafios políticos e econômicos enfrentados pelo país. Os dados trazidos pelas PNADs mostram que houve redução na renda per capita da população brasileira (passando de R 803,36 em 2014 para $\mathrm{R} \$$ 746,84 em 2015) e ingresso de 4,1 milhões de pessoas na pobreza, sendo que, deste total, 1,4 milhão de pessoas ingressaram na extrema pobreza. Esses dados alertam para a necessidade as [sic] políticas públicas voltadas ao crescimento do emprego e da renda, sem deixar de lado o combate à desigualdade, tendo em vista a estagnação do índice de Gini entre 2014 e 2015 (IPEA, 2017, p. 9).
\end{abstract}

Portanto, ainda que o princípio da igualdade tenha surgido nas revoluções políticas dos séculos XVII e XVIII, seja um dos pilares da democracia moderna e indissociável da noção de Justiça, apenas a previsão no texto frio da lei não vem se mostrando suficiente. A história tem mostrado que, no Brasil, as igualdades de condições não são as mesmas.

Recentes estudos sobre a desigualdade no País entre 2001 e 2015, realizados pela equipe de Thomas Piketty com o Instituto de Pesquisa Econômica Aplicada (IPEA), mostram que a renda média anual de toda a população é de $\mathrm{R} \$ 35$ mil, mas o grupo do 1\% mais rico (1,4 milhão de pessoas, aproximadamente) tem renda anual acima de R 287 mil. O 0,1\% mais rico (140 mil pessoas) tem renda superior a R\$ 1,4 milhão, dados que evidenciam que a concentração do capital é muito alta (CARNEIRO; LIMA, 2017, p. 1).

Como já mencionado, o problema não é a desigualdade em si, mas identificar as razões concretas para que ela exista (PIKETTY, 2014, p. 26). Nesse sentido, faz-se necessário refletir a respeito da igualdade material, pois embora o texto Constitucional tenha a previsão de igualdade entre os seres humanos, deve-se buscar a equiparação concreta, assim reduzindo as desigualdades sociais.

Não basta proteger somente a igualdade formal, mas também a igualdade material, que é mais ampla e demanda a necessidade de se produzir a igualdade por meio de políticas públicas.

Implementar o direito de igualdade é de grande importância para uma democracia:

A implementação do direito de igualdade é tarefa fundamental a qualquer projeto democrático, já que em última análise a democracia significa a igualdade no exercício dos direitos civis, políticos, econômicos, sociais e culturais. A busca democrática requer 
fundamentalmente o exercício em igualdade de condições de direitos elementares (PIOVESAN, 2005, p. 52).

Piketty (2014) adverte que há muitos processos econômicos, políticos e sociais que atuam como forças importantes na dinâmica de longo prazo da distribuição que merecem nossa atenção. Forças essas que têm contribuído para uma piora da desigualdade mundial e a uma tendência para sua piora no século XXI.

No Brasil, a Reforma Trabalhista, da forma como aprovada, pode ser uma dessas forças, pois ela é preocupante quando se pensa em desigualdade social, dadas algumas alterações imputadas às relações de trabalho, como mostrado na seção 1 deste artigo. Teme-se que elas possam apontar não apenas para a precarização da mão de obra, mas também para o ato de dificultar o acesso à Justiça.

Nesse sentido, preocupa a possibilidade de retrocesso social, podendo a Reforma alcançar justamente o oposto ao anunciado: o aumento da desigualdade social. Em um país no qual o nível de desigualdade é comparável ao da África do Sul e do Oriente Médio, fica-se bastante distante de alcançar um dos principais objetivos da República, anunciados no art. $3^{\circ}$ da CF/88.

É muito preocupante a negociação direta entre empregado e empregador, assumindo-se apenas que todos são iguais perante a lei e ignorando-se a igualdade substantiva ou material entre esses envolvidos. Isso seria interpretar de forma equivocada a CF/88, pois não se pode aplicar apenas literalmente o texto constitucional, mas sim, de forma sistêmica e teleológica, como lembra Barroso (2011).

Portanto, deve ser levada em consideração a valorização do trabalho humano, como forma de assegurar a existência digna do trabalhador, observando-se os ditames da justiça social. Do contrário, o caminho conflita com o objetivo constitucional de redução das desigualdades sociais, ante a possibilidade, conforme já exposto em tópico anterior, de serem sonegados direitos trabalhistas fundamentais no momento da negociação direta entre empregado e empregador.

Igualdade leva à liberdade e somente com liberdade é possível ao trabalhador negociar com seu patrão sobre suas condições de trabalho. A liberdade, observada por William Cowper (apud SEN, 2000, p. 337), pode ser compreendida da seguinte forma: "Fredom has a thousand charms to show. That slaves, howe'er contented, never know." ${ }^{\prime 1}$.

Conhecida por seu caráter “cidadão”, a CF/88 marcou a retomada democrática no País, afirmando a legitimidade dos direitos civis e políticos e a importância do Estado em garantir esses direitos aos cidadãos. Nesse sentido, deve-se ter em mente que “além de criar uma certa ordem

11 Tradução livre: “A liberdade tem mil encantos a mostrar. Que escravos, por mais satisfeitos, nunca hão de provar”. 
jurídica, toda Constituição necessita produzir e manter a coesão sociopolítica, enquanto prérequisito ou condição de viabilidade de qualquer sistema jurídico” (HESSE, 1992, p. 9), o qual a Constituição produz e mantém, merecendo ser respeitada e obedecida.

Desse modo, é importante o papel das instituições para que seja possível atingir a igualdade tão resguardada na CF/88 e, dessa forma, viabilizar o desenvolvimento, com a redução das desigualdades, como se abordará a seguir.

\section{DESENVOLVIMENTO E A IMPORTÂNCIA DAS INSTITUIÇÕES}

No século XXI, o conceito de desenvolvimento pressupõe a combinação de crescimento autossustentado; mudanças estruturais dos padrões de produção; aperfeiçoamento tecnológico; avanços sociais, políticos e institucionais; bem como a melhoria generalizada da condição humana, como resume Adelman (2000).

Críticas de autores como Amartya Sen (2000) e outros, que enfatizam o conceito de desenvolvimento humano, somam-se às de teóricos como Ignacy Sachs (2002), que destaca a importância de levar em conta a necessidade de preservação do potencial do capital natural e a limitação do uso dos recursos não renováveis, sistematizando a ideia de um desenvolvimento sustentável e pressionando para que o conceito de desenvolvimento seja ampliado. Ou seja, a noção de desenvolvimento deve incorporar outras dimensões, além do crescimento econômico. Assim, o desenvolvimento deve ser pensado de forma ampla, considerando objetivos como liberdade, paz, segurança, proteção da natureza e justiça social.

Mas por que alguns países alcançaram esse desenvolvimento, e outros não? A resposta a essa importante questão é bastante desafiadora. Mostra a Nova Economia Institucional (NEI) que ela passa pela compreensão da influência das instituições nas decisões dos agentes econômicos.

Nessa linha, Acemoglu e Robinson (2012), preocupados com as grandes diferenças de padrão de vida ao redor do mundo, discutem o papel das instituições construídas pelo homem ao longo da história. Mas o que são instituições? Segundo a NEI, são as normas, padrões, hábitos e/ou costumes de uma sociedade, embora não haja uniformidade quanto ao uso desse termo:

\footnotetext{
Não há um consenso, entretanto, entre os autores, quanto à definição exata da ideia. Dada a diversidade das abordagens que essa teoria comporta, instituições são definidas ora como normas ou padrões de comportamento, ora como formas institucionais, ora como hábitos e costumes sociais (ESTEVES, 2010, p. 99).
}

Para um dos principais teóricos dessa escola de pensamento, Douglas North (1994), as instituições são estruturas compostas de regras formais (como regulamentos, leis e constituições) e 
informais (como as convenções e códigos de conduta), além de mecanismos de enforcement desses dois tipos de normas ${ }^{12}$. As organizações, por sua vez, são formadas por indivíduos com propósitos comuns e que buscam um determinado objetivo ${ }^{13}$, podendo ser políticas, econômicas, sociais, educativas, etc.

Assim como em North (1990), a análise histórica é muito importante para Acemoglu e Robinson (2012), que argumentam que boas “regras do jogo” podem produzir incentivos para uma alocação eficiente dos recursos disponíveis. Nesse sentido, as instituições, entre as quais o direito, são fundamentais para o sucesso ou o fracasso no desenvolvimento de uma sociedade.

Os autores buscaram construir uma teoria sobre por que algumas nações são prósperas, enquanto outras fracassaram e têm um enorme número de pessoas pobres. Tentaram oferecer uma teoria simples, mas não simplória, usando-a para explicar as principais características do desenvolvimento econômico e político mundial, embora reconheçam que esse é um fenômeno social complexo para o qual encontram-se diversas causas.

A teoria de Acemoglu e Robinson (2012) tem como elemento central o elo entre instituições econômicas e políticas inclusivas e prosperidade. Por instituições econômicas inclusivas entendemse aquelas com maiores chances de conduzir ao crescimento econômico, fomentando a atividade econômica, o aumento da produtividade e a prosperidade:

Instituições econômicas inclusivas, como as encontradas na Coreia do Sul ou nos Estados Unidos, são aquelas que possibilitam e estimulam a participação da grande massa da população em atividades econômicas que façam o melhor uso possível de seus talentos e habilidades e permitam aos indivíduos fazer as escolhas que bem entenderem. Para serem inclusivas, as instituições econômicas devem incluir segurança da propriedade privada, sistema jurídico imparcial e uma gama de serviços públicos que proporcionem condições igualitárias para que as pessoas possam realizar intercâmbios e estabelecer contratos, além de possibilitar o ingresso de novas empresas e permitir a cada um escolher sua profissão (ACEMOGLU; ROBINSON, 2012, p. 79).

As instituições extrativistas, de outro modo, são aquelas estruturadas para que poucos possam extrair recursos de muitos, como descrevem os autores:

Chamamos essas instituições, cujas propriedades são opostas às daquelas ditas “inclusivas”,
de instituições econômicas extrativistas, por terem como finalidade a extração da renda e da
riqueza de um segmento da sociedade para benefício de outro (ACEMOGLU; ROBINSON,
2012, p. 79-80).

Ou seja, quando prevalecem instituições econômicas inclusivas, como no caso de países como a Coreia do Sul ou Estados Unidos, possibilita-se e estimula-se a participação de um grande

12 Ou seja, mecanismos capazes de fazer cumprir as normas formais e informais.

13 Ao explicar esses conceitos, North (1990) utiliza o exemplo de uma disputa esportiva, em que as instituições são definidas como as regras do jogo, enquanto seus jogadores são as organizações. 
número de pessoas em atividades econômicas, levando-se em consideração seus talentos e habilidades e permitindo que os indivíduos façam as próprias escolhas. Quando prevalecem instituições econômicas extrativistas, tem-se a extração da renda e da riqueza de um segmento da sociedade para benefício de outro.

Como exemplo, os autores citam o caso do México, em que, à semelhança de outros países latino-americanos, prevaleceu o autoritarismo e a herança colonialista, com as elites locais mais preocupadas em assegurar a permanência do modelo que as favorece no poder, do que modificar as instituições coloniais em favor do desenvolvimento do país. Em decorrência, tem-se uma instabilidade institucional no México, caracterizada pela insegurança jurídica histórica no que diz respeito ao direito de propriedade, bem como a ausência de autoridade e controle estatal para arrecadar impostos que assegurem os serviços públicos necessários e/ou estimulem o empreendedorismo, diferentemente do que ocorreu com os Estados Unidos.

Desse modo, dependendo das instituições, aqui entendidas como as "regras do jogo”, podese resultar num círculo vicioso de exclusão ou de desenvolvimento. Quando prevalecem instituições extrativistas, as elites que delas se beneficiam assumem o controle do Estado e impõem à sociedade uma trajetória de desenvolvimento desigual e um controle do poder que lhes proporciona grandes lucros e riqueza, com expropriação dos ativos alheios e o estabelecimento de monopólios (ACEMOGLU; ROBINSON, 2012, p. 84).

A Reforma Trabalhista, como instituição jurídica, política e econômica, precisa ser inclusiva. Não resta dúvida que as instituições devem ser eficientes para definir as relações de mercado e orientar investimentos privados, mas é também imprescindível assegurar direitos sociais de um padrão civilizatório mínimo. Assim, devem ajudar a reduzir as desigualdades econômicas e sociais, norteando políticas públicas pautadas nos ideais democráticos estipulados na ordem constitucional, respeitando o catálogo de direitos e garantias individuais e coletivas por ela definidos.

Ainda que a Reforma em análise fosse capaz de produzir crescimento econômico, ele não pode ser considerado um fim em si mesmo, mas sim um meio para promover a melhoria da vida das pessoas e das liberdades que elas desfrutam, como sustenta Sen (2000).

Essa liberdade tem conceito multiforme e envolve considerações sobre processos e oportunidades substantivas. Então, em uma visão que pode ser complementar à de Acemoglu e Robinson (2012), Sen (2000) destaca que diversos atores sociais contribuem para o processo de desenvolvimento, por meio de seus efeitos sobre o aumento e a sustentação das liberdades individuais. 
Neste aspecto, pode a negociação entre empregado e empregador, com a intervenção mínima do Estado, contribuir para o crescimento e, consequentemente, para o desenvolvimento, como foi anunciado no discurso oficial em favor da Reforma Trabalhista?

Acredita-se que não, pois não há desenvolvimento com o patamar elevado de desigualdade como a brasileira. Ao definir que, mediante acordo e sob o princípio da intervenção mínima do Estado na autonomia da vontade coletiva, possam ser “negociados” diversos pontos como a duração diária do trabalho (art. 59) ou, por exemplo, os previstos no art. 611-A (banco de horas; intervalo intrajornada; adesão ao Programa Seguro-Emprego (PSE); plano de cargos, salários e funções compatíveis com a condição pessoal do empregado, bem como identificação dos cargos que se enquadram como funções de confiança; regulamento empresarial; representante dos trabalhadores no local de trabalho; teletrabalho, regime de sobreaviso, e trabalho intermitente; remuneração por produtividade, incluídas as gorjetas percebidas pelo empregado, e remuneração por desempenho individual; modalidade de registro de jornada de trabalho; troca do dia de feriado; enquadramento do grau de insalubridade; prorrogação de jornada em ambientes insalubres, sem licença prévia das autoridades competentes do Ministério do Trabalho; prêmios de incentivo em bens ou serviços, eventualmente concedidos em programas de incentivo; e participação nos lucros ou resultados da empresa), está sendo considerada a igualdade material?

A CF/88, ao assegurar diversos direitos, trouxe a igualdade formal, mas a justa negociação deve pressupor igualdade material para que a autonomia seja assegurada. Quer dizer, sem a igualdade material é impossível exercer a igualdade formal de empregado e empregador em uma negociação, como a que pressupõe a nova legislação trabalhista.

Igualdade material requer a aplicação de uma justiça redistributiva, buscando mecanismos para equiparar os desiguais, e compensar a desigualdade, na proporção em que se desigualam. Como ensina Weber (1999), eminente teórico da ação social, as desigualdades sociais são resultantes das posições relativas dos diversos tipos de mercados e, sobretudo, das ações estratégicas, ora coletivas, ora individuais, em contexto organizacional e de poder.

Deixar isso para o mercado é ignorar que a relação entre os atores econômicos não é apenas indireta, por meio dos preços, mas exige a construção de instâncias, instituições que as regulem. Nesse sentido, ensina Abramovay (2004, p. 48): “As questões centrais de uma economia descentralizada não podem ser resolvidas pela experiência e erro dos mecanismos mercantis: elas exigem formas variadas de coordenação".

Faz-se necessário, então, que os direitos fundamentais sejam limites à flexibilização irrestrita de acordos firmados entre empregado e empregador. O Estado deve assegurar esses direitos, por meio 
de políticas públicas voltadas à redução da desigualdade social, como a educação de qualidade e outras políticas distributivas.

Não há desenvolvimento se aos trabalhadores brasileiros não forem assegurados meios para que, no momento de negociar com os seus empregadores, protejam-se de "acordos” que precarizam suas condições de trabalho. Com direitos sonegados, não surgirão empregos decentes, nem a realização plena da cidadania. Com subempregos poderá até haver o crescimento econômico, mas jamais o desenvolvimento, como sustentado por Amartya Sen.

Nesse sentido, faz-se necessário que a Reforma Trabalhista, ao permitir a negociação direta entre empregado e empregador, esteja aliada à uma política de justiça distributiva, como forma de garantir uma igualdade material. Somente assim ela será capaz de gerar trabalho decente e respeitar os preceitos constitucionais, com o fomento do desenvolvimento econômico e social e em favor da redução da desigualdade social.

\section{CONSIDERAÇÕES FINAIS}

A CF/88 assegura os direitos de igualdade e liberdade individual. A Reforma Trabalhista, por sua vez, ao defender a intervenção mínima do Estado, possibilitou a flexibilização de direitos trabalhistas, mediante negociação direta entre empregado e empregador, mas preocupa que essa negociação possa gerar empregos e ocupações que não contemplem a ideia de trabalho decente, agravando a desigualdade, conclui este presente artigo.

Ao elevar os direitos dos trabalhadores à categoria de direitos fundamentais, a Constituição limitou o exercício dos poderes do empregador à negociação flexibilizadora das condições de trabalho. Mais ainda, instituiu garantias para efetivar esses direitos, como a proibição de retrocesso social. Nesse sentido, a valorização do trabalho trazida pela CF/88 requer atentar para o patamar mínimo representado pelo conceito da OIT para trabalho decente, mostrado neste artigo.

Porém, ainda que o crescimento econômico do País seja retomado, não há nenhuma garantia de desenvolvimento econômico e social com as relações trabalhistas pautadas nas bases trazidas pela Reforma, tendo em vista que o subemprego que dela pode advir frustra o direito de liberdade de escolhas que é inerente ao desenvolvimento, como sustentado por Amartya Sen.

Hipossuficiente, o trabalhador não está em igualdade de condições nas negociações com o empregador em uma negociação direta e, sem a possibilidade de intervenção, na forma proposta na lei, a situação poderá se agravar. 
O desenvolvimento requer que as instituições estejam bem alicerçadas, que as "regras do jogo” apontem para um círculo virtuoso de inclusão e de redução de desigualdades. Caso contrário, as elites que se beneficiam de instituições extrativistas assumem o controle do Estado e impõem à sociedade um desenvolvimento desigual, com grandes lucros e riqueza às custas de expropriação dos ativos alheios.

A regulação das relações trabalhistas precisa ser inclusiva, compatibilizando o sistema capitalista com direitos sociais de um padrão civilizatório mínimo e, nesse sentido, ajudar a reduzir as desigualdades econômicas e sociais.

O crescimento econômico não pode ser considerado um fim em si mesmo, mas sim um meio de melhoria da vida das pessoas e das liberdades que desfrutam, ensina Sen (2000).

Nesse contexto, é importante que, na negociação entre empregados e empregadores, sejam respeitados os direitos fundamentais dos primeiros, sendo de suma importância políticas públicas que equilibrem a relação capital e trabalho e, assim, assegurem empregos decentes. Do contrário, não haverá desenvolvimento.

Há quase 30 anos, a CF/88 estabeleceu, em seu texto, tudo que é necessário para que, de fato, nas relações de trabalho, a liberdade e a igualdade formal que a constituição assegura sejam alcançadas, devendo a nova legislação trabalhista ser interpretada conforme esses ditames constitucionais, para que se possa alcançar o desenvolvimento nos moldes propostos por Amartya Sen e defendidos neste artigo.

\section{REFERÊNCIAS}

ABRAMOVAY, Ricardo. Entre Deus e o diabo: mercados e interação humana nas ciências sociais. Tempo social, v. 16, n. 2, p. 35-64, 2004.

ACEMOGLU, Daron; ROBISON, James A. Por que as nações fracassam: as origens do poder, da prosperidade e da pobreza. Tradução Cristiana Serra. Rio de Janeiro: Elsevier, 2012.

BARROSO, Luís Roberto. Curso de Direito Constitucional Contemporâneo: os conceitos fundamentais e a construção do novo modelo. 3. ed. São Paulo: Saraiva, 2011.

BONAVIDES, Paulo. Curso de Direito Constitucional. 28 ed. São Paulo. Editora Malheiros, 2013.

BRASIL. Constituição da República Federativa do Brasil de 1988. Disponível em: <https://goo.gl/HwJ1Q>. Acesso em: 21 dez. 2017.

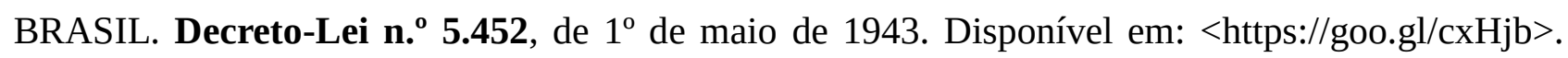
Acesso em: 21 dez. 2017. 
BRASIL. Lei 13.467, de 13 de julho de 2017. Disponível em: <https://goo.gl/7y7uUA>. Acesso em: 21 dez. 2017.

BRASIL. Medida Provisória n. ${ }^{\circ}$ 808, de 14 de novembro de 2017. Disponível em: <https://goo.gl/KJmjJC>. Acesso em: 21 dez. 2017.

BRASIL. Presidência da República. Discurso do Presidente da República, Michel Temer, durante cerimônia de sanção da Lei de Modernização Trabalhista - Palácio do Planalto. Disponível em: <https://goo.gl/WeXm6N>. Acesso em: 21 dez. 2017.

BRASIL. Senado Federal. Consulta Pública. Disponível em: < https://goo.gl/ZgEbME>. Acesso em: 22 dez. 2017.

CARNEIRO, Mariana; LIMA, Flávia. Desigualdade no Brasil é escolha política. Folha de São Paulo, São Paulo, 24 de setembro de 2017. Caderno Mercado. Disponível em: <https://goo.gl/w7k8zY>. Acesso em: 3 mar. 2018.

CURY, Anay; SILVEIRA, Daniel. PIB cresce 0,1\% no $3^{\circ}$ trimestre, na terceira alta seguida. Portal G1. São Paulo e Rio de Janeiro, 01 de dezembro de 2017. Caderno Economia. Disponível em: $<$ https://goo.gl/6A4GKz>. Acesso em: 2 dez. 2017.

DELGADO, Maurício Godinho; DELGADO, Gabriela Neves. A reforma trabalhista no Brasil: com comentários à Lei n. 13.467/2017. São Paulo: LTr, 2017.

DWORKIN, Ronald. Levando os Direitos a sério. São Paulo: Martins Fontes, 2002.

ESTEVES, Heloisa Borges Bastos. Economia e Direito: Um Diálogo Possível. Rio de Janeiro, 2010, 252f. Tese de Doutorado. Universidade Federal do Rio de Janeiro (Programa de Pós-Graduação em Economia).

FERNANDES, Anais; CASTANHO, William. Estoque de ações cai na Justiça do Trabalho. Folha de São Paulo, São Paulo, 17 de abril de 2018. Caderno mercado. Disponível em: $<$ https://goo.gl/Bf2yVq>. Acesso em: 28 mar. 2018.

INSTITUTO BRASILEIRO DE GEOGRAFIA E ESTATÍSTICA (IBGE). Pesquisa Nacional por Amostra de Domicílios Contínua (Pnad Contínua). Disponível em: <https://goo.gl/AvXxjN>. Acesso em: 28 mar. 2018.

INSTITUTO BRASILEIRO DE GEOGRAFIA E ESTATÍSTICA (IBGE). Tabela 2 - Taxa Trimestral (variação em volume em relação ao mesmo trimestre do ano anterior - \%). Dados preliminares - $3^{0}$ Trimestre de 2017. Disponível em: <https://goo.gl/YVbj7i>. Acesso em: $21 \mathrm{dez}$. 2017.

INSTITUTO DE PESQUISA ECONÔMICA APLICADA (IPEA). Fundação João Pinheiro. Programa das Nações Unidas para o Desenvolvimento (PNUD). Radar IDHM 2017. Disponível em: <https://goo.gl/y4wAAK>. Acesso em: $10 \mathrm{dez} .2017$. 
KANT, Immanuel. Fundamentação da metafísica dos costumes. Tradução Paulo Quintela. Crítica da razão pura e outros textos filosóficos, vol. XXV, coleção Os Pensadores. São Paulo: Abril Cultural, 1974.

NORTH, Douglass C. Custos de transação, instituições e desempenho econômico. Rio de Janeiro: Instituto Liberal, p. 1-25, 1994.

NORTH, Douglass C. Institutions, institutional change and economic performance. Cambridge: Cambridge University Press, 1990.

ORGANIZAÇÃO INTERNACIONAL DO TRABALHO (OIT). Trabalho decente. Disponível em: <https://goo.gl/n1hV16>. Acesso em: $10 \mathrm{dez} .2017$.

PIKETTY, Thomas. O capital no século XXI. Rio de Janeiro: Intrínseca, 2014.

PIOVESAN, Flavia. Ações afirmativas da perspectiva dos direitos humanos. Cadernos de Pesquisa, São Paulo, v. 35, n. 124, p. 43-55, Apr. 2005.

ROMITA, Arion Sayão. Direitos fundamentais nas relações de trabalho. São Paulo: LTr, 2007.

SACHS, Ignacy. Caminhos para o desenvolvimento sustentável. Rio de Janeiro: Garamond, 2002.

SARLET, Ingo Wolfgang. A eficácia dos direitos fundamentais. Uma teoria geral dos direitos fundamentais na perspectiva constitucional. 12. ed. Porto Alegre: Livraria do Advogado Editora, 2015.

SEN, Amartya. Desenvolvimento como liberdade. São Paulo: Companhia das Letras, 2000.

WEBER, Max. Economia e sociedade: fundamentos da sociologia compreensiva. V. 1. Brasília: UnB, p. 209-227, 1999.

Ana Elizabeth Neirão Reymão Mestre em Economia (UNICAMP), Doutora em Ciências Sociais (UnB), professora no Programa de Pós-Graduação em Direito, Políticas Públicas e Desenvolvimento do Centro Universitário do Pará (CESUPA) e da Faculdade de Economia da Universidade Federal do Pará (UFPA). Grupo de pesquisas CNPq Emprego, Subemprego e Políticas Públicas na Amazônia (PPGD-CESUPA).E-mail: bethrey@uol.com.br

Shirley da Costa Pinheiro Juíza do Trabalho Substituta no Tribunal Regional do Trabalho da $8^{a}$ Região. Mestranda em Direito, Políticas Públicas e Desenvolvimento Regional (CESUPA). Especialista em Direito do Trabalho e Processual do Trabalho (Universidade Estácio de Sá). E-mail: shirley.pinheiro@trt8.jus.br 